Insignia Journal of International Relations

Vol. 7, No.1, April 2020, 1-16

P-ISSN: 2089-1962; E-ISSN: 2597-9868

\title{
Diplomasi Indonesia Berbasis Program Cross Border Tourism dalam Meningkatkan Kunjungan Wisatawan Mancanegara
}

\author{
Elyta \\ Fakultas Ilmu Sosial dan Ilmu Politik, Universitas Tanjungpura \\ Email: elyta@fisip.untan.ac.id \\ Ully Nuzulian \\ Fakultas Ilmu Sosial dan Ilmu Politik, Universitas Tanjungpura \\ Email: Ully.nuzulian19@gmail.com
}

\begin{abstract}
Abstrak
Aruk Sajingan Indonesia telah menghadapi tantangan tentang minimnya kunjungan wisatawan mancanegara. Hal tersebut dikarenakan Aruk termasuk pintu masuk darat yang hanya mendapatkan nomor urut keempat dari lima pintu masuk darat yang ada di Indonesia, Sebagai upaya meningkatkan kunjungan wisatawan manca negara melalui pintu masuk darat maka Indonesia melakukan diplomasi melalui program cross border tourism. Berdasarkan hal tersebut maka penelitian ini bertujuan untuk menganalisa implementasi diplomasi Indonesia berbasis program cross border tourism dalam meningkatkan kunjungan wisatawan mancanegara batas di wilayah perbatasan Aruk Sajingan Kabupaten Sambas Kalimantan Barat Indonesia. Peneliti menggunakan metode kualitatif, teknik pengumpulan data dengan menggunakan teknik wawancara teknik observasi dan teknik dokumentasi. Hasil penelitian ini menemukan bahwa diplomasi Indonesia berbasis program cross border tourism telah meningkatkan kunjungan wisatawan mancanegara di wilayah border Aruk Sajingan Kabupaten Sambas Kalimantan Barat Indonesia telah dilakukan oleh multitrack diplomacy yaitu pemerintahan, pelaku bisnis, dan masyarakat. Implementasi diplomasi melalui pemerintah berlandaskan pada tiga tingkatan regulasi yaitu tingkatan lokal, nasional dan internasional. Lebih lanjut implementasi diplomasi melalui bisnis dilakukan oleh The Association of Indonesian Tours and Travel Agencies (Asita) dan dioperasikannya pasar belampar yang berlokasi dekat dengan Pos Lintas Batas Negara (PLBN) Aruk Indonesia, Asita selaku pelaku bisnis telah mempromosikan daya tarik wisata yang dimiliki desa di Aruk Sajingan dan telah mengajak para wisatawan mancanegara untuk berbelanja di pasar belampar. Implementasi diplomasi melalui masyarakat dilakukan oleh komunitas Generasi Pesona Indonesia (GenPI) dan Generasi Wonderful Indonesia (GenWI) dengan menyebarkan potensi cross-border tourism melalui media digital. Dengan demikian multitrack diplomacy telah menyebabkan wisatawan mancanegara tertarik berkunjung ke perbatasan Aruk Indonesia, hal tersebut menyebabkan meningkatnya sektor pariwisata lintas batas.
\end{abstract}

Kata kunci: diplomasi, multitrack, cross border tourism, pelabuhan darat, Aruk Sajingan

\begin{abstract}
Aruk Sajingan Indonesia has faced challenges about the lack of foreign tourist arrivals. That is because Aruk is a entrance which only gets the fourth serial number out of five entrances in Indonesia. In an effort to increase foreign tourist arrivals through land entrances, Indonesia conducts diplomacy through cross border tourism programs. Based on this, this study aims to analyze the implementation of Indonesian diplomacy based on cross border tourism programs in increasing border tourist arrivals in the Aruk Sajingan border region, Sambas Regency, West Kalimantan Indonesia. Researchers used qualitative methods, data collection techniques using interview techniques observation techniques and documentation techniques. The results of this study found that Indonesian diplomacy based on cross border tourism programs had increased foreign tourist arrivals in the Aruk Sajingan border region of Sambas Regency, West Kalimantan, Indonesia, which was carried out by multitrack diplomacy, namely government, businessman, and society. The implementation of diplomacy through the government is based on three levels of
\end{abstract}


regulation, namely local, national and international levels. Furthermore, the implementation of diplomacy through business is carried out by The Association of Indonesian Tours and Travel Agencies (Asita) and the operation of the belampar market, which is located close to the Aruk Indonesia Cross-Border Station (PLBN), Asita as a business person has promoted the tourist attraction of villages in Aruk Sajingan and has invited foreign tourists to shop at the belampar market. The implementation of diplomacy through the community is carried out by the Generasi Pesona Indonesia (GenPI) and Generasi Wonderful Indonesia (GenWI) communities by spreading the potential of crossborder tourism through digital media. Thus multitrack diplomacy has caused foreign tourists to be interested in visiting the Aruk Indonesia border, this has led to an increase in the cross-border tourism sector.

Keywords: diplomacy, multitrack, cross border tourism, land port, Aruk Sajingan

\section{Pendahuluan}

Posisi geografis kepulauan Indonesia diapit oleh Benua Asia dan Benua Australia. Indonesia termasuk negara kepulauan, kondisi terkini pulau Indonesia yang telah terdaftar di Perserikatan Bangsa Bangsa terdiri dari 13.466 pulau (Badan Pusat Statistik, 2019). Berdasarkan Rencana Strategis Kementerian Pariwisata Indonesia tahun 2018-2019, posisi geografis dan jumlah kepulauan Indonesia tersebut berpotensi mendukung pariwisata sebagai kekuatan Indonesia (Kementerian Pariwisata RI, 2018). Hal tersebut menjadikan pengembangan pariwisata yang menjadi daya magnet wisatawan mancanegara untuk berkunjung ke Indonesia.

Bambang Brodjonegoro selaku Kepala Badan Perencanaan Pembangunan Nasional (Bappenas) periode 2016-2019 menyatakan pariwisata dari tahun 2014 sampai 2018 termasuk kedalam tiga sektor yang diprioritaskan selain pertanian dan manufaktur (Bisnis.com, 2019). Dengan demikian Pariwisata telah menjadi alternatif kekuatan Indonesia. Penguatan kekuatan perekonomian dan politik Indonesia melalui pariwisata dilakukan dengan mengaplikasi diplomasi untuk mempromosikan potensi negara Indonesia di tataran internasional.

Diplomasi dalam lingkup studi Hubungan Internasional berperan penting untuk menjalin interaksi dengan negara lain (Gurgu \& Cociuban, 2016). Pariwisata Indonesia telah mendata bahwa tahun 2014 jumlah wisatawan mancanegara sebanyak 9,4 juta orang. Setahun pemerintahan
Jokowi, angka kunjungan naik sebesar 1 juta, hal ini terdata tahun 2015 menjadi 10,4 juta, lebih lanjut pada tahun 2016 terdata 11,5 juta, selanjutnya tahun 2017 naik cukup signifikan menjadi 14,03 juta. Dan tahun 2018 terdata sebanyak 15,8 juta (Indonesia.go.id, 2019). Data ini menunjukkan peningkatan dalam jumlah wisatawan mancanegara dan hal ini merupakan prestasi bagi diplomasi Indonesia dalam mempromosikan pariwisara.

Namun jumlah kedatangan wisatawan mancanegara ke Indonesia melalui pintu masuk darat (landport) pada tahun $2018 \mathrm{di}$ Aruk masih tergolong rendah yakni berada pada peringkat keempat dari lima landport yang ada. Tercatat bahwa pada tahun 2018 terdapat 12.329 wisatawan manca negara yang masuk melalui landport Aruk. Sementara itu wisatawan mancanegara yang masuk melalui landport Jayapura ialah sebesar 104 075, melalui Atambua sebesar 85.914 dan Entikong sebesar 23.213 (Badan Pusat Statistik, 2019). Lebih lanjut perbatasan identik dengan kemiskinan sehingga menyebabkan maraknya ancaman keamanan manusia seperti ditemukannya kasus perdagangan perempuan (Elyta, 2012). Pengelolaan perbatasan disinyalir belum dikelola secara komprehensif negara (Elyta, Almutahar, \& Saing, 2019). Melihat kondisi tersebut, pemerintah kemudian mulai menggalakan program cross border tourism agar dapat mendukung peningkatan jumlah wisatawan mancanegara yang masuk melalui wilayah border Aruk Sajingan tersebut. 
Program cross border tourism sendiri sudah sukses diterapkan di negara luar, seperti Prancis yang berhasil mendatangkan $50 \%$ wisatawan mancanegara dari program tersebut. Demikian pula keberhasilan program cross border tourism ini di negara lain seperti datangnya wisatawan mancanegara sebesar 51\% di Belgia, 45\% di Thailand, dan $60 \%$ di Malaysia (Detiknews.com, 2019). Berdasarkan keberhasilan dari negara-negara tersebut, Indonesia kemudian mencoba menerapkan program cross border tourism untuk meningkatkan kunjungan wisatawan mancanegara sehingga program ini telah menjadi program prioritas. Dengan menjadikan cross border sebagai prioritas pariwisata disinyalir dapat menjadikan daya magnet bagi wisatawan mancanegara maka untuk ini kekuatan dari cross border berupaya dianalisis dengan mengaplikasikan diplomasi cross border tourism. Namun, Indonesia masih mempunyai "pekerjaan rumah" sebagai upaya meningkatkan cross border tourism.

Studi terdahulu yang pernah dilakukan terkait upaya peningkatan cross border tourism tersebut di antaranya ialah peneitian yang dilakukan di kawasan perbatasan Sota di Merauke. Penelitian tersebut bertujuan untuk mengetahui kendala yang menghambat pengembangan kawasan perbatasan Sota di Merauke. Hal tersebut dilakukan berdasarkan kondisi pengelolaan kawasan perbatasan di distrik Sota yang berbatasan langsung dengan Papua Nugini yang belum memperlihatkan hasil yang baik, meskipun berbagai program telah dicanangkan pemerintah daerah Merauke untuk mengembangkan kawasan ini sebagai kawasan wisata (Dewi \& Rachmawati, 2018).

Penelitian selanjutnya ialah penelitian yang dilakukan di Turki-Yunani untuk mengeksplorasi peluang dan manfaat dari kolaborasi pemasaran destinasi yang ada di daerah perbatasan Turki-Yunani. Hasil penelitian tersebut telah mengidentifikasi katalisator dan mengidentifikasi keuntungan dari pemasaran tujuan lintas batas yang sukses, seperti kedekatan sejarah, budaya, atraksi dan lokasi (Kozak \& Buhalis, 2019).

Penelitian lain dilakukan di Republik Dominika dan perbatasan Haiti. Penelitian tersebut bertujuan untuk mengetahui korelasi antara faktor sikap terhadap pariwisata perbatasan, faktor nilai yang dirasakan oleh wisatawan, kepuasan dan loyalitas pengunjung di tempat tujuan (del Río, Agüera, Cuadra, \& Morales, 2017). Sementara itu pada penelitian kali ini terdapat kebaharuan dalam penelitian yakni penulis menganalisis tentang implementasi diplomasi Indonesia berbasis program cross border tourism dalam meningkatkan kunjungan wisatawan mancanegara batas di wilayah border Aruk Sajingan Kabupaten Sambas Kalimantan Barat Indonesia.

\section{Kerangka Pemikiran}

Diplomasi adalah upaya yang dilakukan oleh sebuah negara yang dilakukan untuk memperjuangkan kepentingan nasionalnya di wilayah (Holstri dalam Idriasih, 2016). Diplomasi dapat dibagi menjadi dua jenis yakni soft diplomacy dan hard diplomacy. Soft diplomacy merupakan diplomasi yang dilakukan dengan penyelesaian secara damai di antaranya melalui isu kebudayaan, pendidikan, bahasa, atau pun ekonomi. Hard diplomacy adalah diplomasi yang dilakukan dengan peperangan seperti melalui agresi militer dan (Hadi dalam Sinulingga, 2017). Contoh dari Hard diplomacy ialah penggunaan kekuatan militer. Sedangkan soft diplomacy cenderung lebih ke arah penggunaan kekuatan untuk menarik pihak lain dengan nilai atau mempengaruhi agenda pilihan politik yang membuat pihak lain tertarik. Dengan demikian dapat kita lihat bahwa soft diplomacy lebih bersifat coopt dari pada coersive. Namun soft diplomacy tidak sama dengan memengaruhi (influence). Ia lebih dari sekedar bujukan (persuasion) (Nye dalam Dewi \& Issundari, 2016). 
Dalam rangka menganalisis implementasi diplomasi Indonesia melalui program cross border tourism dalam meningkatkan pariwisata lintas batas di wilayah border Aruk Sajingan, Kabupaten
Sambas, Kalimantan Barat, Indonesia, penulis menggunakan teori multitrack diplomacy. Literatur multitrack diplomacy dapat dilihat dalam gambar di bawah ini:

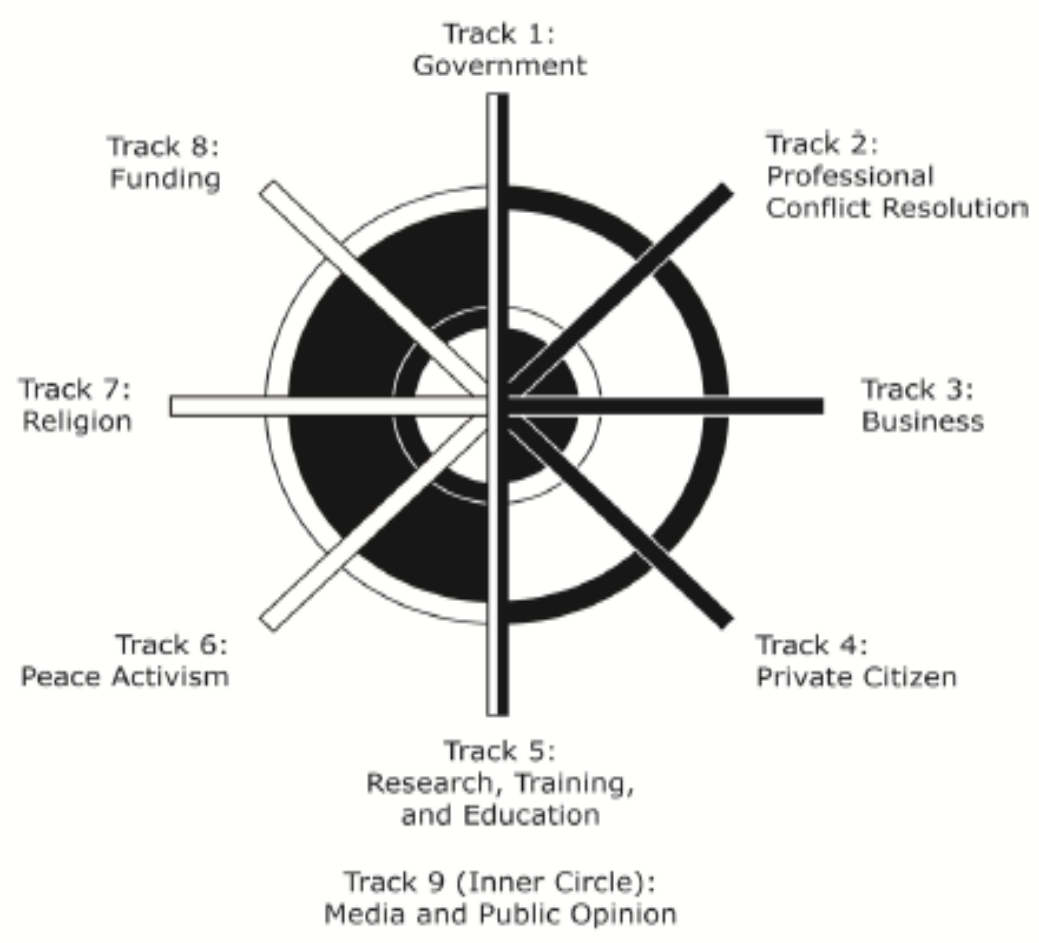

Sumber: The Institute for Multi-Track \& Diplomacy, 2015.

\section{Gambar 1 \\ Bagan Multitrack Diplomacy}

Berdasarkan gambar tersebut, multitrack diplomacy merupakan sebuah model implementasi pariwisata di tataran global. Di dalamnya meliputi peran-peran berbagai pemangku kepentingan sesuai kesembilan jalur tersebut merupakan kinerja secara sistematis dan sinergis. Penelitian ini terfokus pada tiga track yaitu pemerintah, pelaku bisnis, dan masyarakat.

\section{Metode Penelitian}

Penelitian ini bertujuan untuk menganalisis implementasi diplomasi Indonesia melalui program cross border tourism dalam meningkatkan pariwisata lintas batas di wilayah border Aruk Sajingan, Kabupaten Sambas, Kalimantan Barat, Indonesia. Untuk menganalisis tujuan penelitian tersebut, penulis menggunakan metode deskriptif dengan pendekatan kualitatif. Pendekatan ini dilakukan untuk memahami dan menganalisis suatu fenomena sosial atau pun perilaku manusia. Ada tiga teknik penelitian dalam pengumpulan data yaitu pengumpulan data melalui teknik wawancara, studi literatur, dan observasi. Teknik wawancara yang digunakan adalah wawancara mendalam 
dengan berpanduan pada instrumen yakni pedoman wawancara terkait dengan multitrack diplomacy pada program cross border tourism. Narasumber penelitian ini yaitu Wakil Bupati Kabupaten Sambas Kalimantan Barat Indonesia, Kepala Bidang Lembaga dan Pemasaran Dinas Pariwisata, Pemuda dan Olahraga Kabupaten Sambas Kalimantan Barat Indonesia, pengurus GenPI Kalimantan Barat Indonesia, dan dua orang wisatawan dari Malaysia. Studi literatur digunakan dengan mengkaji sumber-sumber tulisan dari jurnal dan berita online mengenai multitrack diplomacy pada program cross border tourism. Lebih lanjut, observasi dilakukan dengan mengobservasi kondisi Pasar Belampar dan kondisi PLBN Aruk. Penelitian ini dilaksanakan dari tanggal 14 Mei 2019 sampai 20 Oktober 2019 di Kecamatan Sajingan, Kabupaten Sambas, karena Sajingan Besar adalah kawasan yang berbatasan langsung dengan Malaysia dan telah menjadi kawasan pengembangan pembangunan di Kabupaten Sambas. Sajingan Besar merupakan pintu masuk border antara Indonesia dan Malaysia selain beberapa daerah lain di Kalimantan Barat dan sudah ditetapkan sebagai lokasi yang mengadopsi program cross border tourism.

\section{HASIL DAN PEMBAHASAN \\ Sejarah dan Perkembangan Festival Cross Border Tourism}

Border area dan cross border area adalah dua konsep yang berbeda, Perbedaan dari border area dan cross border area tersebut terlihat pada gambar berikut ini:

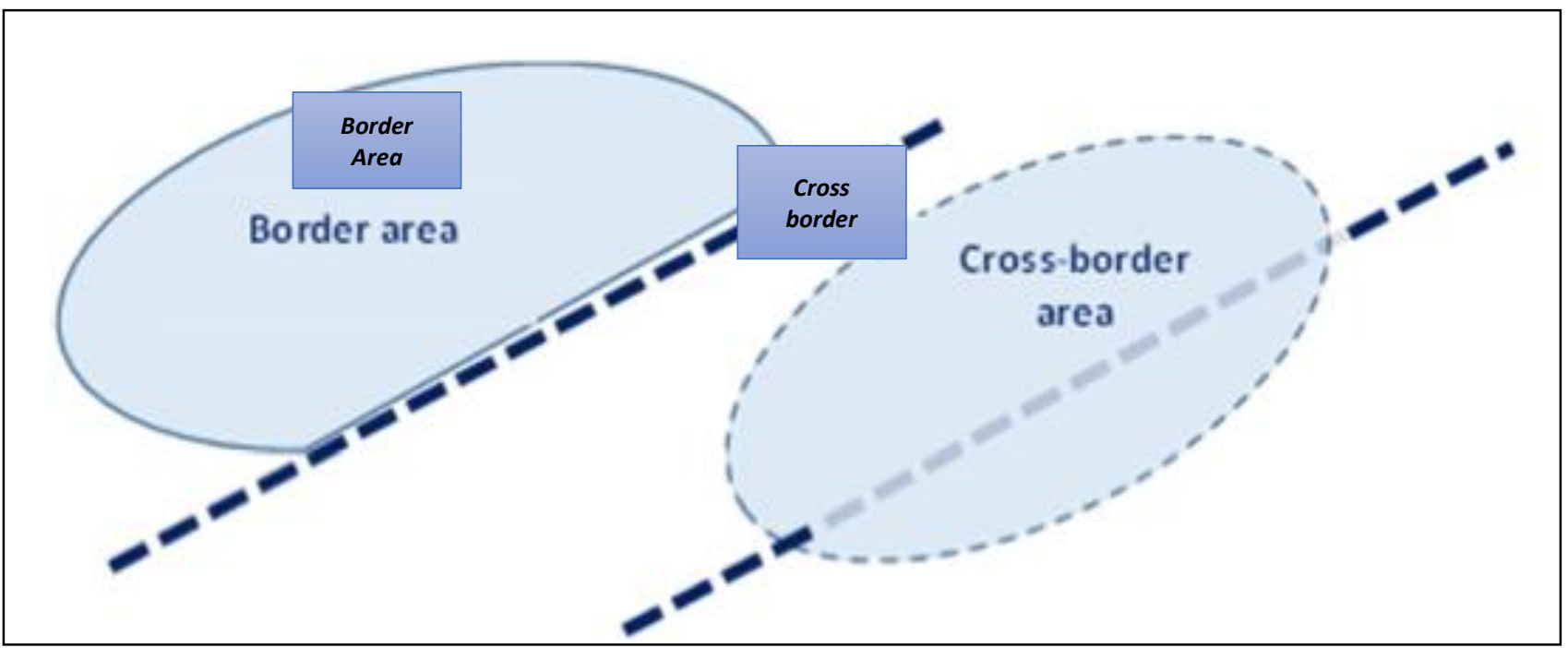

Sumber: Studzieniecki, 2017.

\section{Gambar 2}

Perbedaan Konsep Area Perbatasan dan Area Lintas Batas

Dari gambar tersebut, perbatasan suatu negara berhubungan dengan border area dan cross border. Namun, border area dan cross border adalah dua hal yang berbeda. Border area terletak di dekat perbatasan suatu negara. Di sisi lain, cross border melibatkan dua atau lebih negara (Palmowski dalam Studzieniecki, 2017).
Selanjutnya cross border tourism adalah subjek dari banyak disiplin ilmu, termasuk ekonomi, geografi, ilmu politik, dan hukum. Masalah ini semakin sering dibahas dalam literatur akademis, dokumen negara dan internasional serta publikasi lainnya. Namun, akademisi jarang berusaha untuk mendefinisikan fenomena ini. Akibatnya, 
ada banyak interpretasi mengenai konsep pariwisata lintas batas (Studzieniecki, 2017). Sejak tahun 2015, Presiden Joko Widodo mulai mengarahkan fokus pengembangan pariwisata lintas batas atau cross border tourism. Ketua Umum Apkasi (Asosiasi Pemerintah Kabupaten Seluruh Indonesia) Abdullah Azwar Anas mengungkapkan bahwa program cross border tourism yang merupakan inisiasi dari pemerintah tersebut didukung penuh oleh kabupaten-kabupaten di wilayah perbatasan. Wisatawan mancanegara yang diandalkan dari festival tersebut di antaranya adalah Malaysia, Filipina, Thailand, Papua Nugini, dan Timor Leste. Bahkan Deputi Pemasaran Mancanegara Kementerian Pariwisata RI I Gde Pitana mengatakan bahwa di tahun 2017 terdapat 217 festival cross border tourism yang dilakukan bersama-sama di 30 titik daerah perbatasan dan delapan wilayah lainnya (Balitravelnews.com, 2017).

Kementerian Pariwisata RI kemudian melaksanakan agenda launching Calender Festival Cross Border 2018 di Ballroom Hotel Alila Jakarta pada tanggal 8 Desember 2017. Kalender tersebut dibuat untuk mendorong terwujudnya tujuan untuk menstimulus pembangunan infrastruktur wilayah perbatasan yang sesuai dengan program Nawacita yang dijalankan pemerintahan Jokowi-JK. Dalam kalender tersebut telah dipetakan sebanyak 214 festival yang digelar di 29 area perbatasan Indonesia (Liputan6.com, 2017). Pada tahun 2019, pemerintah melalui Kementerian Pariwisata RI semakin meningkatkan perhatiannya pada pengembangan pariwisata lintas batas atau cross border tourism melalui pelaksanaan Festival wisata berskala lokal, nasional, regional, maupun global (Suara.com, 2018).

Kementerian Pariwisata Republik Indonesia juga telah menggelar kegiatan focus group discussion (FGD) di Kabupaten Sanggau Kalimantan Barat. FGD ini membahas Weekend Market Cross Border yang ada di PLBN Kalimantan Barat, salah satunya adalah Aruk. Luaran dari kegiatan ini adalah (1) pemasukan devisa negara sebanyak Rp 240 triliun; (2) menambah tenaga kerja sejunlah 13 juta dan (3) kehadiran wisatawan mancanegara ditargetkan berjumlah 20 juta. Lebih lanjut, dalam FGD tersebut juga dibahas mengenai co-branding bus Damri dengan rute utama branding Wonderful Indonesia melalui jalur internasional serta promosi media sosial atau mobile digital (Traveldetik.com, 2019b).

Festival cross border tourism telah dilaksanakan di Kabupaten Sambas, tepatnya di Aruk Sajingan. Festival Cross Border di Aruk Sajingan yang dilaksanakan pada tahun 2019 telah berhasil mengundang 2.361 wisatawan yang berasal dari Malaysia. Berdasarkan data dari Pos Imigrasi Aruk, pada hari pertama festival terdapat 583 orang wisatawan dari Malaysia yang masuk menggunakan paspor dan 200 orang lainnya masuk menggunakan Passanger Moving System (PMS). Pada hari kedua, jumlah wisatawan mengalami peningkatan, yakni terdapat 978 orang yang masuk menggunakan paspor dan sebanyak 600 orang yang masuk menggunakan PMS (Suarakarya.id, 2019b). Dengan demikian program Cross Border Tourism diharapkan menjadi salah satu strategi efektif dalam menarik minat wisatawan mancanegara untuk mengunjungi berbagai kawasan perbatasan.

\section{Implementasi Diplomasi Indonesia melalui Program Cross Border Tourism}

Dari penelitian yang telah dilakukan, penulis menemukan bahwa implementasi diplomasi Indonesia berbasis program cross border tourism dalam meningkatkan kunjungan wisatawan mancanegara batas di wilayah border Aruk Sajingan, Kabupaten Sambas, Kalimantan Barat, dilakukan melalui pemerintah, pelaku bisnis, dan masyarakat. Penjelasan tersebut dapat dilihat pada pembahasan berikut.

\section{Diplomasi Indonesia melalui Pemerintah}


Diplomasi adalah tata kelola dalam studi hubungan internasional (Prasetya \& Estriani, 2018). Tata kelola ini dilakukan oleh salah satu aktor, yaitu pemerintah yang melakukan regulasi. Pola regulasi yang dilakukan berupa government to government (G2G) dengan pendekatan pengembangan pariwisata lintas batas melalui mandat diplomasi publik (Fulda, 2019). Upaya diplomasi dilakukan oleh pemerintah merujuk pada regulasi tentang pengembangan perbatasan. Hasil penelitian menunjukkan bahwa diplomasi Indonesia melalui pemerintah berlandaskan pada tiga regulasi yaitu regulasi di tingkat lokal, nasional, dan internasional. Di dalam regulasi tersebut, isu pariwisata, khususnya pariwisata lintas batas, termasuk 10 isu strategis yang menjadi prioritas nasional

Berdasarkan wawancara dengan $\mathrm{Hj}$. Hairiah selaku wakil bupati Sambas menyebutkan bahwa, "visi besar dari Presiden Republik Indonesia yaitu pembangunan Indonesia". Merujuk pada wawancara tersebut, maka dapatlah dijelaskan bahwa visi Presiden Republik Indonesia berdasarkan pada ide Nawacita Presiden Jokowi. Salah satu upaya yang telah berhasil yang dilakukan oleh pihak pemerintah pusat dan daerah untuk memajukan wilayah perbatasan yaitu pembangunan PLBN Aruk yang diresmikan pada 17 Maret 2017. PLBN tersebut merupakan daya pikat wisatawan mancanegara untuk mengunjungi perbatasan Aruk.

Untuk regulasi tingkat internasional, pemerintah telah mengawal regulasi yang mendukung pengembangan pariwisata perbatasan melalui Rencana Strategis (Renstra) Pariwisata Association of Southeast Asian Nations (ASEAN) 20112015. Renstra tersebut memuat kebutuhan untuk mengkonsolidasikan keuntungan yang telah dibuat dan mengambil pendekatan yang lebih strategis untuk mengatasi tantangan yang dihadapi pengembangan ASEAN sebagai kompetitif, berkelanjutan, dan lebih inklusif secara sosial-ekonomi dan tujuan wisata terpadu. Ini berarti bahwa akan diperlukan untuk mengatasi konektivitas utama, lintas batas, investasi, tujuan dan pengembangan produk, standar kualitas, keselamatan dan keamanan, infrastruktur pariwisata, warisan alam dan budaya, dan masalah perubahan iklim (ASEAN, 2015).

Dari landasan-landasan regulasi yang telah diupayakan oleh pemerintah Indonesia tadi kemudian pemerintah mulai menggencarkan event cross border di Aruk yakni melalui Festival Cross Border Aruk 2019. Festival pariwisata yang diadakan oleh pemerintah di perbatasan Aruk seperti Festival Cross Border Aruk telah dilaksanakan sebanyak 2 kali pada tahun 2019. Festival pertama dilaksanakan pada hari Sabtu tanggal 23 Februari 2019 sampai 24 Februari 2019. Selain menampilkan acara hiburan dari artis ibu kota, seperti Sandrina dan Belinda, pembukaan Festival cross border Aruk Sajingan juga dimeriahkan oleh atraksi Barongsai dari anggota TNI yang dapat dilihat pada foto berikut. 


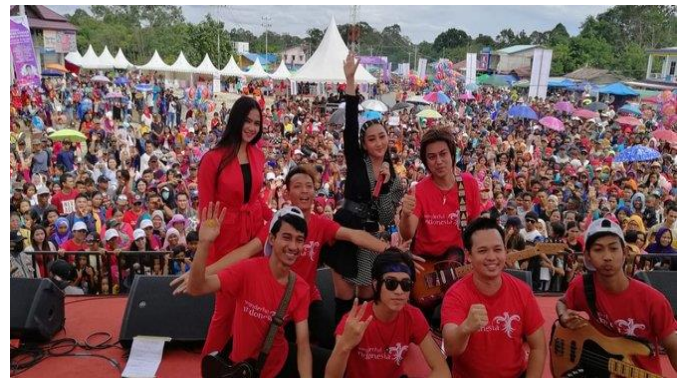

Sumber: Merdeka.com, n.d.

Gambar 3

Penampilan Hiburan dari Penyanyi Sandrina

Festival ini telah mendatangkan wisatawan mancanegara sebanyak 4.154 wisatawan (GNFI.com, 2019). Festival semacam ini merupakan upaya promosi wisata dengan melestarikan kearifan lokal. Festival yang diadakan telah menarik minat para wisatawan mancanegara dengan menampilkan pengelolaan berbagai potensi yang ada di kawasan perbatasan dari aspek budaya. Penyajian potensi tersebut mendeskripsikan nilai jual yang dimiliki dan daya tarik yang efektif dalam menjaring para wisatawan mancanegara. Malaysia selaku negara tetangga berpotensi menghadirkan wisatawan mancanegara yang dominan ke kawasan perbatasan Indonesia, mengingat adanya pendekatan emosional dan kondisi geografis. Pendekatan dan kondisi yang dimaksud mengarah pada kemiripan unsur kulturalisasi dan keadaan wilayah kedua negara yang dilalui jalur lintas batas. Pada hari Sabtu, 30 Maret 2019, agenda festival dibuka dengan penyuguhan Tari Rakyat Melayu dan penampilan musik tradisional Sape oleh Talino Poe yang khas. Selain itu, penggelaran tradisi dan seni di Aruk semakin meriah melalui ekshibisi berbagai stand yang dikelola oleh warga setempat selaku pelaku UMKM (Okezone.com, 2019).

Berkaitan dengan PLBN Aruk, Presiden Jokowi telah meresmikan PLBN Aruk pada tanggal 17 Maret 2017. Menurut Presiden Jokowi, bangunan dan

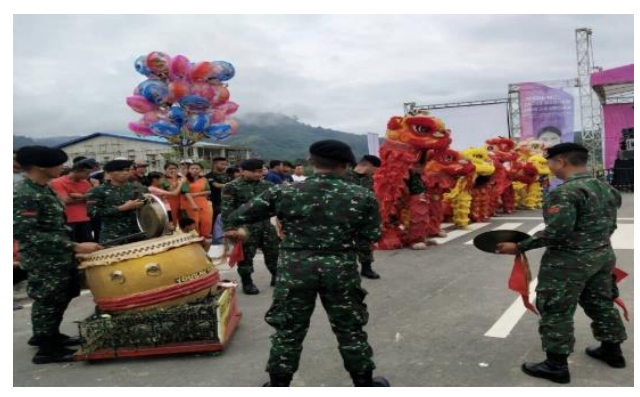

Sumber: Akurat.co, 2019

\section{Gambar 4}

Pertunjukan Tarian Barongsai oleh TNI

desain PLBN Presiden Jokowi adalah paling bagus dan paling megah diantara dua PLBN yang berada di Kalimantan Barat (Tempo.co, 2017). Desain dan bangunan PLBN Aruk yang bagus dan megah menjadi daya tarik wisatawan nusantara dan wisatawan mancanegara untuk berkunjung ke PLBN Aruk. Antusias pengunjung terlihat dari bagaimana banyaknya warga yang berfoto di PLBN Aruk.

Menurut wisatawan mancanegara, desain utama PLBN Aruk yang unik terlihat dari bangunan terdepan PLBN Aruk yang terlihat seperti "kapal selam". Selain itu, desain PLBN Aruk mengadopsi kearifan lokal berupa desain tradisional Rumah Betang yang merupakan rumah adat masyarakat Dayak. Ornamen juga mengadopsi corak ukiran tradisional Dayak. Berdasarkan pendapat dari wisatawan mancanegara dapatlah dijelaskan filosofi dari bangunan PLBN berbentuk seperti kapal selam mengandung makna bahwa alutsista Indonesia siap menjaga keamanan wilayah Republik Indonesia yang bertugas untuk mewujudkan PLBN sebagai garda terdepan negara.

Tidak berhenti pada penyuguhan hiburan tarian daerah, musik lokal, dan pameran stan saja, hari kedua penggelaran Festival Cross Border Aruk yang diselenggarakan pada hari Minggu, 31 Maret 2019, dimeriahkan oleh salah satu penyanyi dangdut dalam negeri yaitu Juwita 
Bahar. Kehadiran artis terkenal ini semakin menarik minat para wisatawan mancanegara untuk hadir pada agenda tahunan di Aruk, Kabupaten Sambas. Pengadaan festival terbilang berhasil dan mampu mencapai target yang dicanangkan, terutama pengenalan destinasi wisata setempat. Potensi pariwisata yang dimiliki dalam kawasan perbatasan ini diasumsikan sebagai permata di beranda terdepan Indonesia, dimana terdapat kekayaan alam seperti pesona Pantai Temajuk dan Riam berasap (Traveldetik.com, 2019a).

Dengan demikian festival yang telah diselenggarakan melalui dukungan berbagai pihak berdampak besar pada keberhasilan program cross border tourism. Kemeriahan festival tersebut yang mengundang para wisatawan mancanegara semakin meningkatkan minat untuk berkunjung kembali, sekaligus mendorong para wisatawan mancanegara untuk mengeksplorasi objek pariwisata andalan di kawasan perbatasan Aruk Indonesia. Selain festival tersebut, pesona destinasi alam Air Tejun Riam Merasap juga menjadi salah satu lokasi pariwisata di kawasan perbatasan Kabupaten Sambas yang eksotik dengan dihiasi panorama hutan tropis istimewa Kalimantan juga dilengkapi fasilitas untuk kenyamanan pengunjung

Akses pasar dapat menciptakan kestabilan ekonomi (Elyta \& Zulkarnaen, 2016). Terlihat wisatawan mancanegara maupun nusantara juga telah berbelanja di Pasar Belampar, yang mana penjual pasar tersebut adalah masyarakat Aruk di perbatasan. Lebih lanjut wisatawan mancanegara juga bisa berbelanja kerajinan anyaman, tenun, songket, kuliner khas Sambas seperti bubur pedas dan jeruk Sambas. Kondisi tersebut mengajak para wisatawan mancanegara untuk tidak hanya berkunjung ke destinasi di kota besar yang telah terkenal sebelumnya, namun juga di kawasan perbatasan Indonesia. Tentunya, hasil ini mencerminkan keberhasilan sinergitas antara pemerintah dengan pihak lainnya dalam mengelolah program cross border tourism. Jelas pemerintah telah memfasilitasi promosi destinasi melalui pengadaan festival dan bantuan infrastruktur agar memperlancar perjalanan para wisatawan ke lokasi wisata. Lebih lanjut, terlihat juga bahwa adanya bantuan pihak media dalam menyebarkan informasi pesona cross border tourism yang dimiliki Indonesia secara luas, juga masyarakat yang membantu pengelolaan tempat pariwisata seperti menjaga kelestarian alam.

Di samping pelaksanaan kegiatan dalam negeri yang mengundang para wisatawan mancanegara, Indonesia berperan aktif dalam mempromosikan potensi cross border tourism di luar negeri. Konsulat Jenderal Indonesia (Konjen RI) di Kuching menyelenggarakan Festival Wonderful Indonesia 2019 di depan Waterfront Kuching pada tanggal 29 hingga 31 Maret 2019, dengan target kehadiran pengunjung sebanyak 300.000 orang. Penyelenggaran kegiatan ini memperoleh dukungan langsung dari Dewan Bandaraya Kuching Utara (DBKU). Dalam Festival ini, Indonesia menampilkan berbagai pameran dari kerajinan khas UMKM Indonesia juga menawarkan enam paket wisata dengan masing-masing keunggulan yang ditujukan untuk menarik wisatawan agar datang ke Indonesia (Suarakarya.id, 2019a).

Acara cross border pada tahun 2019 ini merupakan festival ke-enam, yang diadakan pertama kali pada tahun 2013. Terdapat perpaduan budaya dalam festival ini yang menyuguhkan berbagai pesona wisata Indonesia dan agenda Warisan Pintar Old Kuching atau Old Kuching Smart Heritage. Selain memperoleh apresiasi dari Konsulat Jendral Republik Indonesia (Konjen RI), acara ini terbilang sukses karena telah dihadiri oleh 350.000 pengunjung yang tak hanya dari masyarakat Sarawak saja, melainkan juga juga dihadiri oleh masyarakat Malaysia Semenanjung. Momen tahunan ini memanfaatkan media cetak, seperti poster dan flyer maupun tayangan LED di seluruh 
kawasan waterfront dalam mewujudkan promosi festival cross border Kalimantan Barat (Okezone.com, 2019).

Festival Wonderful Indonesia 2019 telah digelar di waterfront kota Kuching Malaysia telah memberikan manfaat yang menguntungkan bagi kedua belah negara, baik negara Indonesia maupun Malaysia. Selain memperkenalkan pesona pariwisata Indonesia di Kuching, penyelenggaran kegiatan ini sekaligus bertujuan dalam mempererat hubungan kedua negara terlihat dari dukungan DBKU selaku perwakilan pihak Kuching dan agenda lokal Kuching. Festival ini juga bertepatan dengan perayaan kegiatan nasional daerah Sarawak, sehingga hal ini memberikan peluang yang tepat sasaran dalam mengalokasikan tempat penyelenggaraan kegiatan yang dikenal paling sering dikunjungi oleh masyarakat.

Pengadaan Festival Wonderful Indonesia 2019 di Kuching Malaysia, diadakan sesuai dengan ciri khas daerah yang ada di Indonesia, karena setiap daerah di Indonesia memiliki daya tarik yang berbeda. Pada pengadaan Festival Wonderful Indonesia 2019, Indonesia telah menyediakan paket lengkap untuk para wisatawan guna memahami potensi yang dimiliki negara Indonesia dalam bidang budaya maupun wisata melalui penampilan konser musik, penyajian berbagai hasil olahan lokal Indonesia seperti cinderamata hingga kuliner tradisional, serta promosi destinasi pariwisata yang ada di Indonesia. Pihak Indonesia mempromosikan destinasi wisata melalui paket wisata dengan harga terjangkau agar menarik para turis dalam menikmati pesona destinasi yang ada di Indonesia. Terlepas dari peluang yang dimanfaatkan oleh pemerintah, festival ini menguntungkan masyarakat Sarawak yang terhibur dan telah menikmati serangkaian agenda dalam penggelaran acara tersebut.

\section{Diplomasi Indonesia oleh Pelaku Bisnis}

Kegiatan masyarakat perbatasan Aruk Indonesia lebih berorientasi pada negara
Malaysia (Elyta, Sofyan, Rahman, \& Nuzulian, 2018). Suatu negara tidak terlepas dari aktivitas perdagangan lintas batas (Elyta, 2017). Dalam meningkatkan aktivitas perdagangan lintas batas, pemerintah Indonesia telah melakukan diplomasi melalui pelaku bisnis diwilayah perbatasan. Adanya kegiatan bisnis di wilayah perbatasan secara tidak langsung telah memainkan peran penting dalam pertumbuhan pariwisata di perbatasan Indonesia.

Dalam pengembangan pariwisata, pemerintah Indonesia membuka peluang bagi pelaku bisnis untuk menanamkan modalnya, seperti pendampingan desa wisata yang dilakukan oleh The Association of Indonesian Tours and Travel Agencies (Asita). Pendampingan oleh pelaku ekonomi tersebut dilakukan dengan tujuan mendukung peningkatan kualitas produk unggulan desa serta mempromosikan daya tarik wisata yang dimiliki desa (Bisnis.com, 2019). Kehadiran artis-artis Indonesia dalam Festival cross border di Aruk 2019 menjadi sebuah daya tarik mengingat banyak juga masyarakat Serawak yang mengidolakan artis-artis Indonesia, sehingga kegiatan tahunan cross border ini menjadi Festival yang dinantikan dan menjadi pendorong bagi wisatawan mancanegara asal Sarawak. Banyaknya pengunjung yang menghadiri festival tentu semakin mendukung upaya promosi cross border tourism di Indonesia. Ini menjadi kesempatan bagi para agen travel untuk turut menawarkan pesona wisata Indonesia melalui tourism packages dengan promo menguntungkan.

Kepala Bidang Pemasaran Area III Kemenpar Sapto Haryono mengemukan bahwa wisatawan tertarik mengetahui info pariwisata Indonesia dan bersemangat untuk menjawab online survey. Hasil survei yang diadakan pada saat festival terdata kunjungan warga Sarawak/ Malaysia antara lain untuk mengisi waktu luang berjumlah $58 \%$, urusan bisnis berjumlah 20,5\%, dan menemui teman atau kerabat $16,1 \%$. Alasan 
berwisata adalah atraksi $51,1 \%$, berbanding cost 21,4\%, activity 19,8\%, maupun akomodasi 2,7\% (Okezone.com, 2019).

Dengan demikian, festival cross border Aruk merupakan praktek alternatif pemerintah Indonesia yang nyata dalam mencapai target kunjungan 20 juta orang wisatawan mancanegara. Pemerintah Indonesia semakin optimis dalam mempromosikan pariwisata perbatasan karena suksesnya pengadaan festival yang konsisten dan perolehan antusias para pengunjung. Apalagi agenda yang semakin meriah dengan adanya penampilan tarian

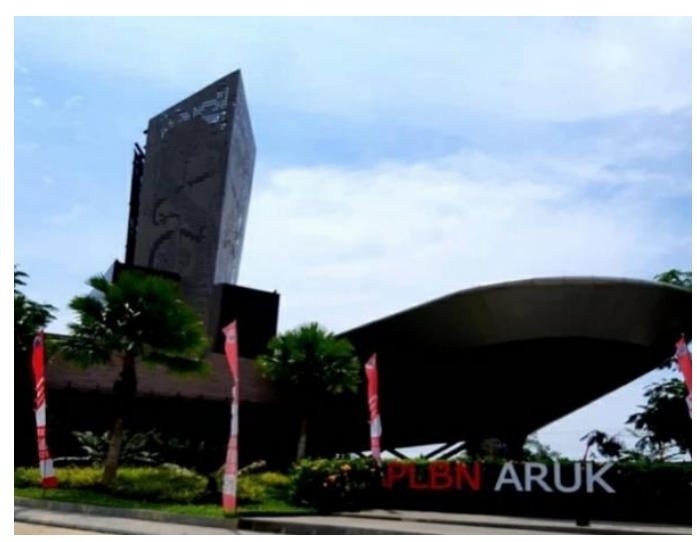

Sumber: Dokumentasi pribadi, 2019.

\author{
Gambar 5 \\ Bangunan PLBN Aruk
}

Selain potensi dari PLBN, terdapat pula pasar lintas batas yang dikelola oleh pelaku bisnis yang turut menarik minat wisatawan mancanegara (Elyta \& Razak, 2019). Salah satu pekerjaan masyarakat Aruk adalah sebagai pengrajin anyaman. Perempuan penganyam di Kecamatan Sajingan Besar telah menghasilkan kerajinan anyam yang begitu unik (Elyta \& Razak, 2019). Saat festival cross border tourism dan hari Sabtu dan Minggu, para pengrajin menjual hasil kerajian anyamannya di Pasar Belampar, yang berdekatan dengan PLBN Aruk. Dinas Koperasi, UKM Perindustrian, dan tradisional dari suku Melayu, hiburan musik etnis Dayak, maupun penampilan artis dalam negeri, sehingga mengundang para wisatawan untuk hadir di acara tersebut. Selain menampilkan hiburan tarian dan musik, upaya menarik minat para pengunjung tersalurkan melalui tampilan budaya maupun berbagai stan kerajinan tangan dan Pasar Belampar.

Selanjutnya kegiatan Pasar Belampar termasuk upaya untuk merangsang peningkatan perekonomian masyarakat di perbatasan yang mendatangkan wisatawan mancanegara sebagai konsumennya.

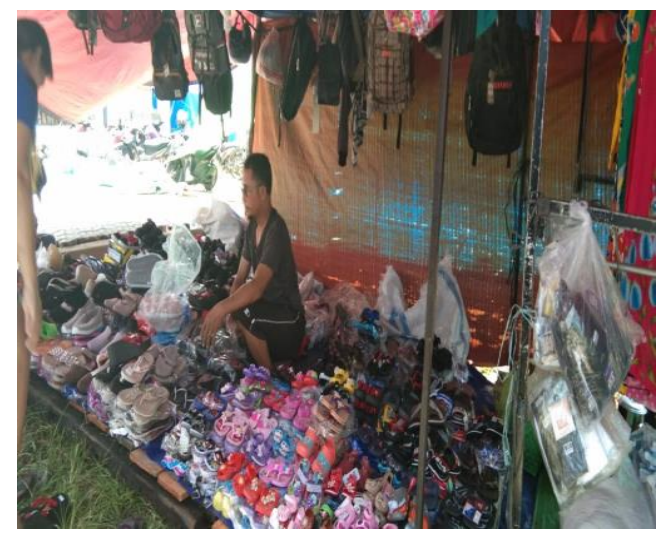

Sumber: Dokumentasi pribadi, 2019.

\author{
Gambar 6 \\ Situasi Pasar Belampar
}

Perdagangan Kabupaten Sambas telah mengoperasikan Pasar Belampar pada 10 11 Maret 2018 di daerah perbatasan Aruk. Adanya Pasar Belampar ini bertujuan untuk meningkatkan perekonomian masyarakat di perbatasan. Ada sekitar 70 orang pedagang yang berasal dari perbatasan Aruk dan wilayah sekitar Kabupaten Sambas. Kegiatan Pasar Belampar adalah menjual barang tanpa membuka toko.

Selain itu, terdapat tuntutan target mengenai penyajian berbagai produk unggulan dari Kabupaten Sambas. seperti kerajinan produk UMKM, komoditas pertanian, dan profil-profil wisata yang 
dapat dipromosikan untuk menarik pengunjung. Target pemerintah terhadap peluang sektor pariwisata melalui keberperanan pelaku bisnis mengacu pada empat ekspektasi, yaitu capaian devisa negara sebesar 15 persen atau setara dengan 240 triliun rupiah, membuka lapangan pekerjaan yang memanfaatkan 13 juta pekerja, keberhasilan atas arus masuknya wisatawan mancanegara yang mencapai 20 juta jiwa, serta daya kompetitif pariwisata yang diakui dunia dengan peringkat ke-30 (Traveldetik.com, 2019b). Target tersebut direalisasikan melalui agenda cross border tourism untuk mempersiapkan program pasar lintas batas atau Market Cross-border yang diposisikan di setiap titik Pos Lintas Batas Nasional (PLBN) termasuk di Aruk, Kabupaten Sambas. Dengan demikian, diplomasi Indonesia telah berjalan dengan dukungan pelaku bisnis, karena Pasar Belampar ikut andil dengan menjual produk khas Kabupaten Sambas.

\section{Diplomasi Indonesia Melalui Masyarakat}

Transformasi global telah membawa perubahan dari aktor yang melaksanakan diplomasi, yang sebelumnya hanya ada interaksi antara aktor negara dan MNC, sampai saat ini muncul aktor non-negara sebagai aktor yang menggerakkan diplomasi ekonomi (Ismail, 2019). Diplomasi ekonomi bertujuan untuk menyejahterahkan ekonomi masyarakat dengan melibatkan aktor negara dan aktor non-negara (Nugraha, 2018). Diplomasi Indonesia melalui masyarakat dilakukan dengan kerja sama antara pemerintah Indonesia melalui Kementerian Pariwisata Indonesia dengan aktor masyarakat melalui komunitas Generasi Pesona Indonesia (GenPI) dan Generasi Wonderful Indonesia (GenWI).

GenPI dan GenWI bertujuan untuk mempromosikan pariwisata Indonesia melalui media digital. Promosi pariwisata telah dilakukan oleh GenPI dan GenWI dengan pola yang mengikuti perkembangan teknologi modern yang mengglobal, lebih dekat dengan wisatawan, dan lebih profesional. GenPi Kalimantan Barat memiliki tugas untuk mempromosikan potensi-potensi pariwisata Kalimantan Barat oleh anggotanya berada di dalam negeri, sedangkan GenWI merupakan wadah pemuda yang anggotanya berada di luar negeri dengan tugas yang sama yakni melakukan promosi pariwisata melalui media digital.

Menteri Pariwisata Arief Yahya menekankan penggarapan potensi pariwisata lintas batas agar dilakukan melalui promosi informasi yang tersedia pada media atau produk elektronik. Regulasi yang dilakukan diantaranya adalah melalui program Go Digital. Program ini dilakukan oleh GenPI dan GenWI dengan tujuan untuk mendorong keterlibatan para stakeholder dalam pengembangan sektor pariwisata tersebut termasuk di perbatasan Aruk, Kabupaten Sambas. Program yang diimplementasikan melalui pemanfaatan teknologi dan informasi berbasis digital ini merupakan langkah strategis yang dilakukan.

Dalam wawancara dengan Yogi selaku pengurus Generasi Pesona Indonesia Kalimantan Barat, ia menyatakan bahwa

"Tujuan GenPI adalah untuk
membantu masyarakat dan
membantu perekonomian UMKM.
Para pemuda dalam wadah GenPI juga
ikut berkontribusi dalam
memperkenalkan pariwisata di
Indonesia, sehingga setiap ada acara-
acara daerah termasuk dari festival
crossboder maka GenPI akan turut
serta di dalamnya secara sukarelawan
dalam naungan kementerian dan
dinas pariwisata."

Kalimantan Barat sendiri memiliki tiga kabupaten yang belum membentuk GenPI tingkat kabupaten/ kota, yakni Bengkayang, Ketapang, dan Kapuas Hulu. Untuk itu, GenPI Kalimantan Barat dan 
Nasional masih mengupayakan pembentukan GenPI di tiga kabupaten tersebut agar promosi pariwisata Indonesia tadi dilakukan oleh pemuda di daerahdaerah.

Selanjutnya, Kementerian Pariwisata mengandalkan keterlibatan wadah GenPi dan GenWi agar mendukung tercapainya target kunjungan wisatawan mancanegara ke Indonesia melalui upaya promosi pariwisata Indonesia melalui pemanfaatan media digital atau digital destination. Program ini merupakan bagian kemitraan GenPI dengan Dinas Kepemudaan, Olahraga, dan Pariwisata Kalimantan Barat yang mempunyai tujuan agar cross border destination dapat dikenal lebih luas oleh masyarakat hingga ke mancanegara (Kemenpar.go.id, 2018). Dengan demikian, potensi wisata lintas batas yang ada di Aruk telah dipromosikan melalui wisata berbasis digital tersebut.

Sementara itu, GenWI berperan dengan mengadakan tour travel, yakni memperkenalkan pariwisata melalui armada travel dengan spanduk GenWI dan slogan Wonderful Indonesia. GenWI juga melakukan promosi melalui media sosial. GenWI Malaysia telah memiliki lebih dari 20 akun instagram yang memiliki ribuan pengikut. Dengan demikian, masyarakat yang mengetahui promosi wisata tersebut melalui platform digital atau dalam hal ini akun media sosial GenWi berada dalam jumlah yang besar. Pada tahun 2018, GenWI Malaysia telah memposting lebih dari 6.000 publikasi wisata melalui akunnya walau baru dibentuk pada tahun 2017. Selain aktif di media sosial internet, GenWI Malaysia juga turut berpartisipasi dalam berbagai Festival pariwisata seperti Sport Tourism Festival, Sales Mission, Festival Absolutely Halal Malaysia (AHM), dan Travel Axpo Wonderful (Liputan6.com, 2019). Hal tersebut disinyalir memberi dampak positif bagi pertambahan jumlah kunjugan wisatawan mancanegara dari Malaysia ke Indonesia.

\section{KESIMPULAN}

Diplomasi Indonesia berbasis program cross border tourism yang telah dilakukan melalui Festival Cross Border Aruk berdampak pada meningkatnya jumlah kunjungan wisatawan mancanegara. Implementasi diplomasi Indonesia berbasis program cross border tourism dalam meningkatkan kunjungan wisatawan mancanegara di wilayah border Aruk Sajingan, Kabupaten Sambas, Kalimantan Barat, Indonesia, dilakukan melalui tiga jalur, yaitu pemerintah, pelaku bisnis, dan masyarakat. Ketiganya melancarkan promosi pariwisata perbatasan serta mempertahankan eksistensi pariwisata perbatasan di ranah pasar yang kompetitif. Implementasi diplomasi melalui pemerintah diselaraskan dengan regulasi dengan berlandaskan pada tiga tingkatan regulasi yaitu tingkatan lokal, nasional, dan internasional. Implementasi diplomasi melalui pelaku bisnis dilakukan oleh The Association of Indonesian Tours and Travel Agencies (Asita) dan pedagang di Pasar Belampar. Implementasi diplomasi melalui masyarakat dilakukan oleh komunitas GenPi dan GenWi dengan menyebarkan informasi pesona crossborder tourism melalui media digital.

Rekomendasi penelitian ini adalah Festival Cross Border Aruk perlu diperlama waktunya menjadi 5 sampai 7 hari. Hal ini karena festival tersebut hanya berlangsung selama dua hari sehingga seakan-akan hanya seremonial untuk menunjukan peningkatan kunjungan wisatawan. Selain itu, secara kualitas, program cross border tourism disinyalir kurang membawa multiplier effect yang berdampak pada perekonomian masyarakat setempat. Walaupun secara kuantitas, program cross border tourism telah menunjukkan peningkatan jumlah wisatawan mancanegara. Rekomendasi selanjutnya yang dapat diberikan terhadap peningkatan pariwisata lintas batas di wilayah perbatasan Aruk Sajingan, Kabupaten Sambas, Kalimantan Barat, Indonesia, 
melalui program cross border tourism ialah memperkaya festival yang sarat akan budaya dan kearifan lokal, seperti yang dilakukan oleh Badan Pariwisata Sarawak (Sarawak Tourism Board).

Dengan peningkatan perekonomian melalui peningkatan wisatawan di daerah perbatasan, pemerintah bisa mengurangi potensi konflik di daerah perbatasan.

\section{DAFTAR PUSTAKA}

\section{Jurnal}

Del Río, J. A. J., Agüera, F. O., Cuadra, S. M., \& Morales, P. C. (2017). Satisfaction in border tourism: An analysis with structural equations. European Research on Management and Business Economics, 23(2), 103-112. DOI: https://doi.org/10.1016/j.iedeen.201 7.02.001.

Dewi, M. A., \& Issundari, S. (2016). Desa Wisata sebagai Aset Soft Power Indonesia. Masyarakat, Kebudayaan dan Politik, 29(2), 64-74. DOI: https://doi.org/10.20473/mkp.v29i2 2016.68-78.

Dewi, M. A., \& Rachmawati, I. (2018). The barriers and strategy of Sota's border tourism area development. Masyarakat, Kebudayaan Dan Politik, 31(4), 400-409. DOI: https://doi.org/10.20473/mkp.v31i4 2018.400-409

Elyta, E. (2012). Penanggulangan Perdagangan Perempuan Di Perbatasan Entikong Kabupaten Sanggau Provinsi Kalimantan Barat: Perspektif Keamanan Manusia. Indonesian Journal of Dialectics IJAD, 2(2), 59-63. Diakses dari http://jurnal.unpad.ac.id/ijad/article/ view/2655/0.

Elyta, E. (2017). Perdagangan Gula Ilegal di Wilayah Perbatasan Entikong Indonesia dan Malaysia. Jurnal Sosiohumaniora, 19(1), 59-63. DOI: https://doi.org/10.24198/sosiohuma niora.v19i1.10747.

\section{Ucapan Terima Kasih}

Penulis mengucapkan terima kasih kepada Universitas Tanjungpura (UNTAN) yang telah mendanai penelitian ini melalui Dana DIPA 2019 UNTAN No. SP DIPA.042.01.2.400955/ 2019 Tanggal 05 Desember 2018.

Elyta, E., Almutahar, H., \& Saing, Z. (2019). National Strength on Construction of International Freight Terminal in Entikong Indonesia. International Journal of Scientific and Technology Research, 8(3), 10-15.

Elyta, E., \& Razak, A. (2019). The Role of Weavers Woman in Strengthening Nationalism Case Study in Sajingan Besar Frontier, Indonesia. Sosiohumaniora, 21(1), 40. DOI: https://doi.org/10.24198/sosiohuma niora.v21i1.19285.

Elyta, E., Sofyan, A., Rahman, I., \& Nuzulian, U. (2018). Nasionalisme Masyarakat Perbatasan di Kalimantan Barat Indonesia. Jurnal Hubungan Internasional Mandala, 1(2), 311-322.

Elyta, E., \& Zulkarnaen. (2016). Political Participation of Border Communities at Sajingan Besar in Election of Representatives Area. Jurnal Penelitian dan Pengembangan Borneo Akcaya, 39-45.

Fulda, A. (2019). The emergence of citizen diplomacy in European union-China relations: Principles, pillars, pioneers, paradoxes. Diplomacy and Statecraft, 30(1), 188-216. DOI: https://doi.org/10.1080/09592296.2 019.1557419.

Gurgu, E., \& Cociuban, A. D. (2016). The Role of Public Diplomacy in International Relations in Full Process of Globalization. Annals of "Spiru Haret". Economic Series, 16(2), 125143. DOI: https://doi.org/10.26458/16210. Idriasih, G. (2016). Diplomasi Indonesia 
Melalui Kampanye Wonderful Indonesia dalam Meningkatkan Pariwisata Indonesia di Dunia Internasional tahun 2011-2015. JOM Universitas Riau, 3(1), 1-15. Ismail, A. (2019). NGO dalam Diplomasi Ekonomi: Implementasi Program Sustainable Development Goals (SDG's) Poin Pengentasan Ketimpangan Sosial di Indonesia. Insignia: Journal of International Relations, 6(1), 1-12. DOI: https://doi.org/10.20884/1.ins.2019. 6.1.1255.

Kozak, M., \& Buhalis, D. (2019). Crossborder tourism destination marketing: Prerequisites and critical success factors. Journal of Destination Marketing and Management, 14(October), 100-392. DOI: https://doi.org/10.1016/j.jdmm.2019. 100392.

Nugraha, C. L. (2018). Penguatan Diplomasi Ekonomi Tiongkok di ASEAN melalui ACFTA Upgrading Protocol. 5(2), 6784.

Prasetya, D. M., \& Estriani, H. N. (2018). Diplomasi Maritim Indonesia dalam Indian Ocean Rim Association (IORA): Peluang dan Tantangan. Insignia Journal of International Relation, 5(2), 96-108. DOI:

https://doi.org/10.24198/intermestic .v2n2.5.

Sinulingga, S. P. (2017). Diplomasi Kebudayaan Indonesia Terhadap Amerika Serikat Melalui Kuliner (Gastrodiplomacy) Tahun 2010-2016). JOM Fisip, 4(2), 1-14. DOI: https://doi.org/https://doi.org/10.39 29/ethz-b-000238666.

Studzieniecki, T. (2017). The promotion of cross-border tourism in Poland. The competition Poland grows beautiful - 7 wonders of the European funds. (January).

\section{Internet}

Akurat.co. (2019). "Festival Cross Border
Aruk-Sajingan Dimeriahkan Atraksi Barongsai Prajurit TNI." Diakses dari https://akurat.co/gayahidup/id536308-read-festival-cross-borderaruksajingan-dimeriahkan-atraksibarongsai-prajurit-tni,

Balitravelnews.com. (2017). "Membangun Daerah Perbatasan Lewat Cross Border Tourism." Diakses dari http://balitravelnews.com/2017/08/15/memba ngun-daerah-perbatasan-lewat-crossborder-tourism/.

Bisnis.com. (2019). "Perkuat Ekonomi, Pariwisata Jadi Sektor Prioritas Tanah Air." Diakses dari https://ekonomi.bisnis.com/read/201 90211/12/887482/perkuat-ekonomipariwisata-jadi-sektor-prioritastanah-air.

Detiknews.com. (2019). “Garap Crossborder Tourism, Apkasi Kolaborasi dengan Kemenpar." Diakses dari https://news.detik.com/berita-jawatimur/d-4613050/garap-crossbordertourism-apkasi-kolaborasi-dengankemenpar.

GNFI.com. (2019). "Festival Crossborder Aruk 2019 Tarik 4.154 WNA ke Perbatasan." Diakses dari https://www.goodnewsfromindonesia .id/2019/02/27/festival-crossborderaruk-2019-tarik-4-154-wna-keperbatasan.

Indonesia.go.id. (2019). "Wisata Indonesia di Mata Dunia." Diakses dari https://www.indonesia.go.id/ragam/ pariwisata/pariwisata/wisataindonesia-di-mata-dunia.

Kemenpar.go.id. (2018). "Siaran Pers : Generasi Pesona Indonesia (GenPI), Sebagai Digital Influencer Kepariwisataan Indonesia." Diakses dari kemenpar.go.id/post/siaranpers-generasi-pesona-indonesiagenpi-sebagai-digital-influencerkepariwisataan-indonesia.

Liputan6.com. (2017). “Kemenpar Siapkan 214 Event Wisata Cross Border 
Sepanjang 2018." Diakses dari https://www.liputan6.com/lifestyle/r ead/3189030/kemenpar-siapkan214-event-wisata-cross-bordersepanjang-2018.

Liputan6.com. (2019, April 28). "Perkuat Kampanye Wonderful Indonesia di Malaysia GenWi Malaysia Lakukan Konsolidasi." Diakses dari https://www.liputan6.com/lifestyle/r ead/3952329/perkuat-kampanyewonderful-indonesia-di-malaysiagenwi-malaysia-lakukan-konsolidasi.

Merdeka.com. (n.d.). "Aksi Sandrina Memukau, Festival Crossborder Aruk 2019 Meriah." Diakses dari https://www.merdeka.com/gaya/aksi -sandrina-memukau-festivalcrossborder-aruk-2019-meriah.html.

Okezone.com. (2019, April 3). "Pengunjung Festival Wonderful Indonesia Di Malaysia Capai 350 Ribu Orang." Diakses dari https://lifestyle.okezone.com/read/2 019/04/03/406/2038542/pengunjun g-festival-wonderful-indonesia-dimalaysia-capai-350-ribu-orang. Suara.com. (2018). "Gandeng GenPI, Kemenpar Garap Potensi Destinasi Digital di Perbatasan." Diakses dari https://www.suara.com/lifestyle/201 8/12/07/120000/gandeng-genpikemenpar-garap-potensi-destinasidigital-di-perbatasan.

Suarakarya.id. (2019a). "Gelar Festival Wonderful Indonesia, Kemenpar Hebohkan Kuching dengan Cita Citata." Diakses dari sindonews.com/read/1391687/34/ge lar-festival-wonderful-indonesiakemenpar-hebohkan-kuching-dengancita-citata-1554028378\%0A.

Suarakarya.id. (2019b, April 2). "Dihadiri
2.361 Wisman, Bupati Sambas Bangga Kepada Kemenpar." Diakses dari https://www.suarakarya.id/detail/89 413/Dihadiri-2361-Wisman-BupatiSambas-Bangga-Kepada-Kemenpar. Tempo.co. (2017). "Resmikan PLBN Aruk, Presiden Jokowi: Ini Paling Bagus.”

Diakses dari nasional.tempo.co/read/857014/res mikan-plbn-aruk-presiden-jokowi-inipaling-bagus.

Traveldetik.com. (2019a). “Usai Nonton Festival Crossborder Aruk, Jangan Lewatkan 10 Destinasi Ini." Diakses dari https://travel.detik.com/travelnews/d-4491425/usai-nontonfestival-crossborder-aruk-janganlewatkan-10-destinasi-ini.

Traveldetik.com. (2019b, April 17). “Jaring Turis Malaysia, Kemenpar Siapkan Weekend Market Cross Border." Diakses dari https://travel.detik.com/travelnews/d-4514974/jaring-turismalaysia-kemenpar-siapkanweekend-market-cross-border.

\section{Laporan Tahunan/Laporan Penelitian} ASEAN. (2015). ASEAN Tourism Strategic Plan 2016-2025. Retrieved from https://www.asean.org/storage/2012 /05/ATSP-2016-2025.pdf

Badan Pusat Statistik. (2019). Statistik Indonesia 2019.

Kementerian Pariwisata RI. (2018). Rencana Strategis 2018-2019 Kementerian Pariwisata. https://doi.org/10.1017/CB0978110 7415324.004

The Institute for Multi-Track, \& Diplomacy. (2015). Annual Report 2015 ITDP Annual Report 2015. 